\section{The effect of alpha-methyl-para-tyrosine on sleep and arousal in the rat}

MARC BRANCHEY and BENJAMIN KISSIN, State University of New York, Downstate Medical Center, Brooklyn, N.Y. 11203

A single intraperitoneal injection of $200 \mathrm{mg} / \mathrm{kg}$ of body weight of $\mathrm{dl}$ alpha-methyl-para-tyrosine in the rat induced a significant increase in NREM sleep without affecting REM sleep. The results support the hypothesis of the existence of a catecholaminergic mechanism of arousal.

There is ample evidence that NREM sleep (nonREM sleep) is controlled by a serotonergic system located in the median raphe (Jouvet, 1969). There is also recent evidence that sleep and arousal depend on a catecholaminergic system located in the mesencephalic reticular formation (Jones, Bobillier, \& Jouvet, 1969). Alpha-methyl-para-tyrosine (AMT) specifically inhibits the synthesis of norepinephrine and dopamine and could, therefore, be expected to increase steep. In the monkey (Weitzman, McGregor, Moore, \& Jacoby, 1969), as well as in the cat (King \& Jewett, 1969), there is some evidence to suggest that the amount of NREM sleep increases after administration of AMT. Marantz \& Rechtschaffen (1967) studied the effect of three injections of $50 \mathrm{mg}$ of $1-\mathrm{AMT} / \mathrm{kg}$ of body weight (BW) at $4-\mathrm{h}$ intervals in the rat. They concluded that there was "a slight suggestion that this drug could produce a total sleep increment" although this trend did not reach statistical significance. A failure to elicit a significant increase in sleep could be related to an inadequate dosage and schedule of administration of the drug. Using the same dosage and schedule of administration as Marantz \& Rechtschaffen (1967), Pirch \& Rech (1968) studied the effect of AMT on the integrated electrocorticogram of the rat. They observed a small increase in the average voltage content that was not statistically significant. When they used a single injection of $100 \mathrm{mg} / \mathrm{kg} \mathrm{BW}$ of l-AMT, they noted a significant increase in the average voltage content. Electrocorticogram recordings showed high voltage, low frequency activity. It seemed

Fig. 1. Percentages of NREM sleep (NR) and REM sleep (R) during the $24 \mathrm{~h}$ following the injection of $200 \mathrm{mg}$ of dl-AMT/kg BW (drug) or an equivalent amount of the solvent (control). thus warranted to explore the possibility that a single administration of $100 \mathrm{mg} / \mathrm{kg} \mathrm{BW}$ of 1-AMT would induce a significant change in sleep patterns in the rat.

\section{METHODS}

Five male Sprague-Dawley rats weighing between $400 \mathrm{~g}$ and $450 \mathrm{~g}$ were inplanted, under pentobarbital anesthesia, with cortical, subcortical, and muscular electrodes. Stainless steel screws were placed unilaterally on the dura over the frontal and occipital cortices and over the olfactory bulb. A single bipolar stainless steel electrode was implanted stereotaxically in the hippocampus. In addition, two small solder disk electrodes were put under the skin on the neck muscles. All leads were soldered to a miniature connector and the assembly was fastened to the skull by acrylic cement and two anchoring screws.

The animals were allowed at least 2 weeks to recover from surgery. They were housed, for the duration of the experiment, in a cage placed in a soundproof chamber, with a lighting schedule of $12 \mathrm{~h}$ of darkness (from 6 p.m. to 6 a.m.) and $12 \mathrm{~h}$ of light (from 6 a.m. to 6 p.m.). The skull pedestal was attached to a cable connected to a mercury pool swivel, allowing the animals freedom of movement. They were adapted to this situation for at least 2 days prior to recording.

Recordings were made with an eight-channel Beckmann polygraph at a speed of $1 \mathrm{~mm} / \mathrm{sec}$. The scoring criteria for wakefulness were high muscular activity, low-amplitude slow waves in the olfactory bulb. The criteria for NREM sleep were low muscular activity, high-amplitude EEG and hippocampal activity, low activity in the olfactory bulb. REM sleep (rapid eye movement sleep) was characterized by a further decrease in muscular activity, a low-amplitude EEG, a very regular activity in the hippocampus (corresponding to the theta rhythm seen at higher speed), and a very low activity in the olfactory bulb. The same criteria have been used in a previous study (Branchey \& Branchey, in press).

dl-AMT methyl ester, used in this study, has the same potency as its parent amino acid, since it is rapidly deesterified in the mammalian body (Corrodi \& Hanson, 1966). It has the advantage of being hydrosoluble. Weissman \& Koe (1965) have reported that a single injection of $100 \mathrm{mg} / \mathrm{kg} \mathrm{BW}$ of 1 -AMT in the rat decreases the levels of norepinephrine and dopamine in the brain. A maximum

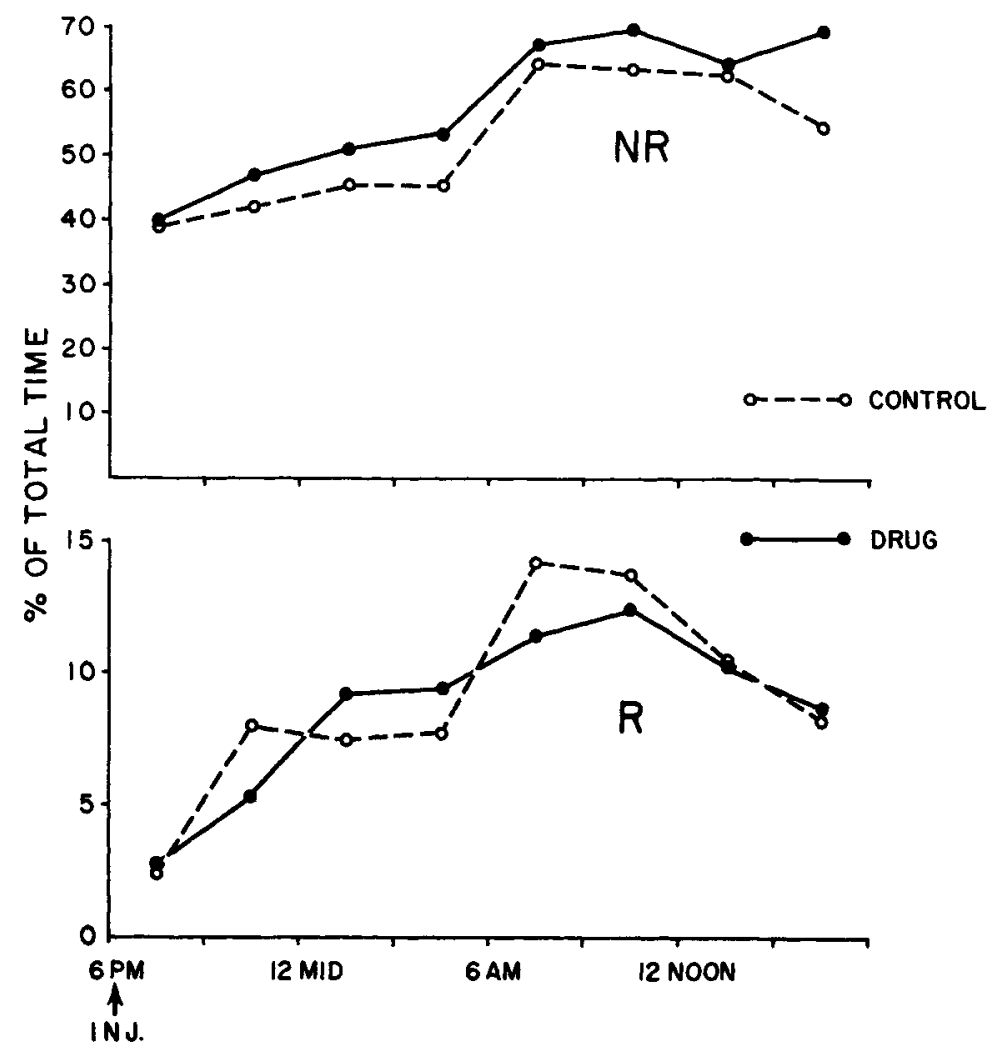


depletion of more than $50 \%$ is reached from 5 to $7 \mathrm{~h}$ after the injection, and a return to normal values is observed after more than $24 \mathrm{~h}$. The same dosage of this drug has been found to have behavioral effects in the rat (Weissman \& Koe, 1965; Rech, Borys, \& Moore, 1966) without inducing any toxicity (Moore, Wright, \& Bert, 1967). A dose of $200 \mathrm{mg} / \mathrm{kg} \mathrm{BW}$ of the racemate, dissolved in $0.9 \% \mathrm{NaCl}$, was used in the experiment. This dose of the racemate corresponds to $100 \mathrm{mg} / \mathrm{kg} \mathrm{BW}$ of the levo form, which is the active isomer (Spector, Sjoerdsma, \& Udenfriend, 1965). Drugs were administered by intraperitoneal injection in a volume of $0.2 \mathrm{cc} / 100 \mathrm{~g} \mathrm{BW}$. Three animals received $200 \mathrm{mg} / \mathrm{kg} \mathrm{BW}$ of dl-AMT at 6 p.m. Forty-eight hours later, they received an equivalent amount of the solvent only. For two other animals, the order of injection was reversed. Sleep was recorded for $24 \mathrm{~h}$ following each injection. None of the animals appeared ill or toxic after the injection of the drug. They all survived the experimental procedure.

\section{RESULTS AND DISCUSSION}

The changes in NREM sleep and REM sleep during the $24 \mathrm{~h}$ period following an injection of $200 \mathrm{mg} / \mathrm{kg} \mathrm{BW}$ of dl-AMT can be seen in Fig. 1. The amount of NREM sleep is increased throughout the whole period, while there is no evidence of a systematic effect on REM sleep. An analysis of variance showed that the drug vs control effect on NREM sleep was significant $(p<0.005)$.

The results support the initial hypothesis that AMT induces an increase in NREM sleep in the rat when the appropriate dosage and schedule of administration are used. As noted above, similar results have been obtained in the cat (King \& Jewett, 1969) and in the monkey (Weitzman et al, 1969). It is likely that the effect of AMT is due to a decrease in synthesis of dopamine, norepinephrine, or both. Disulfiram and alpha-methyl-DOPA, which both interfere with catecholamine synthesis, induce also an increase in NREM sleep in the cat (Dusan-Peyrethon, Peyrethon, \& Jouvet, 1968; Peyrethon-Dusan \& Froment, 1968). Amphetamine, whose action is inhibited by AMT and which acts probably by releasing catecholamines from nerve terminals in the brain (Weissman, Koe, \& Tenen, 1965; Hanson, 1967), is known to increase arousal (Elkes, Elkes, \& Bradley, 1954; Longo \& Silvestrini, 1957) and to antagonize the increase in sleep induced by barbiturates (Barnes \& Meyers, 1964;
Baekeland, 1967). The evidence in favor of an adrenergic mechanism of arousal located in the reticular formation has been reviewed by Dell (1960). More recently, Jones et al (1969) have demonstrated the existence of catecholamine containing neurones in the mesencephalic reticular formation. They reported that the destruction of norepinephrine containing neurones in this area was correlated with a decrease in cortical activation, while the destruction of dopamine containing neurones led to a decrease in behavioral arousal. As AMT decreases the levels of norepinephrine and dopamine, it is likely that the increase in sleep induced by this drug is due to its interference with the electrophysiological and behavioral mechanisms of arousal.

The results confirm also the studies by Marantz \& Rechtschaffen (1967) and Marantz, Rechtschaffen, Lovell, \& Whitehead (1968), who concluded that catecholamine synthesis is not essential for the occurrence of REM sleep in the rat.

\section{REFERENCES}

BAEKELAND, F. Pentobarbital and dextroamphetamine sulfate: Effect on the sleep cycle in man. Psychopharmacologia (Berlin), 1967, 11, 388-396.

BARNES, C. D., \& MEYERS, F. H. Eserine and amphetamine: Interactive effects on sleep time in mice. Science, 1964, 144, 1221-1222.

BRANCHEY, M., \& BRANCHEY, L. Sleep and wakefulness in female rats during pregnancy. Physiology \& Behavior, in press.

CORRODI, M., \& HANSON, L. C. F. Central effects of an inhibitor of tyrosine hydroxylation. Psychopharmacologia (Berlin), 1966, 10, 116-125.

DELL, P. Intervention of an adrenergic mechanism during brain stem reticular activation. In J. R. Vane, G. E. W. Wolstenholme, and M. O'Connor (Eds.), Ciba Foundation symposium on adrenergic mechanisms. London, 1960. Boston: Little, Brown, 1961. Pp. 393-409.

DUSAN-PEYRETHON, D., PEYRETHON, J., \& JOUVET, M. Suppression élective du sommeil paradoxal chez le chat par alpha methyl DOPA. Comptes Rendus de la Société de Biologie (Paris), 1968, 162, 116-118.

ELKES, J., ELKES, C., \& BRADLEY, P. B. The effect of some drugs on the electrical activity of the brain, and on behavior. Journal of Mental Science, 1954, 100, 125-128.

HANSON, L. C. F. Evidence that the central action of amphetamine is mediated via catecholamines. Psychopharmacologia (Berlin), $1967,10,289-297$.

JONES, B. E., BOBILLIER, P., \& JOUVET, M. Effets de la destruction des neurones contenant des cathécolamines du mésencéphale sur le cycle veille-sommeil du chat. Comptes Rendus de la Société de Biologie (Paris), 1969, 63, 176-180.

JOUVET, M. Biogenic amines and the states of sleep. Science, 1969, 168, 32-41.

KING, C. D., \& JEWETT, R. E. Enhancement of slow wave sleep and REM sleep by 1-alpha-methyl-p-tyrosine in cats. Paper presented to the Association for the Psychophysiological Study of Sleep, Boston, Mass., 1969.

LONGO, V. G., \& SILVESTRINI, B. Action of eserine and amphetamine on the electrical activity of the rabbit brain. Journal of Pharmacology \& Experimental Therapeutics, 1957, 120, 160-170.

MARANTZ, R., \& RECHTSCHAFFEN, A. Effect of alpha-methyl-tyrosine on sleep in the rat. Perceptual \& Motor Skills, 1967, 25, 805-808.

MARANTZ, R., RECHTSCHAFFEN, A. LOVELL, R. A., \& WHITEHEAD, P. K. Effect of alpha-methyl-tyrosine on the recovery from paradoxical sleep deprivation in the rat Communications in Behavioral Biology (A), 1968, 2, 161-164.

MOORE, K. E., WRIGHT, P. F., \& BERT, J. K. Toxicologic studies with alpha-methyl-tyrosine, an inhibitor of tyrosine hydroxylase. Journal of Pharmacology \& Experimental Therapeutics, 1967, 155 . 506-515.

PEYRETHON-DUSAN, D., \& FROMENT, J. L. Effets du disulfiram sur les états de sommeil chez le chat. Comptes Rendus de la Société de Biologie (Paris), 1968, 162, 2141-2145.

PIRCH, J. H., \& RECH, R. H. Effect of alpha-methyl-tyrosine on the electrocorticogram of unrestrained rats. International Journal of Neuropharmacology, $1968,7,315-323$.

RECH, R. H., BORYS, M. K., \& MOORE, K. E. Alterations in behavior and brain catecholamine levels in rats treated with alpha-methyl-tyrosine. Journal of Pharmacology \& Experimental Therapeutics, $1966,153,412-419$.

SPECTOR, S., SJOERDSMA, A., \& UDENFRIEND, S. Blockade of endogenous norepinephrine synthesis by alpha methyl tyrosine, an inhibitor of tyrosine hydroxylase. Journal of Pharmacology, 1965, 147, 86-95.

WEISSMAN, A., \& KOE, B. K. Behavioral effects of L-alpha-methyl-tyrosine, an inhibitor of tyrosine hydroxylase. Life Science (Ptl), 1965, 4, 1037-1048.

WEISSMAN, A., KOE, B. K., \& TENEN, S. S. Antiamphetamine effects following inhibition of tyrosine hydroxylase. Journal of Pharmacology \& Experimental Therapeutics, $1966,151,339-352$.

WEITZMAN, E. D., McGREGOR, P., MOORE, C., \& JACOBY, J. The effect of alpha-methyl-para-tyrosine on sleep patterns of the monkey. Life Science (Ptl), 1969, 8, 751-757.

\section{NOTE}

1. The authors wish to thank Dr. Henri Begleiter for his helpful comments in the review of this manuscript. This research was supported by Grants MH-13145 and MH-16477 from the National Institute of Mental Health, USPHS. 